\title{
Experiencias
}

\section{El servicio de escolaridad combinada de la ONCE en Cataluña en época de pandemia: adaptar las formas respetando los criterios}

\author{
ONCE's combined schooling service in Catalonia \\ during the pandemic: adapting procedures \\ while upholding criteria
}

\section{A. Ruf Urbea}

\section{Resumen}

La dificultad para aplicar los mismos criterios de intervención educativa, que eran los rasgos de identidad del Servicio de Escolaridad Combinada (SEC) del Centro de Recursos Educativos para Deficientes Visuales-Centro de Recursos Educativos (CREDV-CRE) de la ONCE en Barcelona antes de la pandemia de covid-19, ha obligado a reformular la metodología de participación, tanto del alumnado como del profesorado. Algunas de las modificaciones propuestas tampoco pudieron llevarse a cabo por impedimentos personales, materiales o normativos. Finalmente, se logró mantener la atención del servicio a distancia en detrimento de la relación presencial. El equipo docente procuró no renunciar a los criterios construidos durante los cursos anteriores. Las dificultades fueron tomadas como incentivos y la satisfacción se basó tanto en los pequeños logros de los alumnos como en la cohesión del equipo para imaginar posibilidades, potencia con la cual nos atrevíamos a afrontar nuevos retos.

\section{Palabras clave}

Covid-19. Servicio de Escolaridad Combinada. Atención presencial. Atención telemática. 


\begin{abstract}
The onset of covid-19 hampered implementation of the educational criteria in place prior to that time in the Combined Schooling Service provided by the ONCE's Educational Resource Centre for People with Visual Disability - Educational Resource Centre, Barcelona. The solution consisted in reformulating the procedures involved in student and teacher participation. Some of the changes proposed could not be implemented due to personal, material or regulatory constraints. Ultimately the service could be delivered in remote format, albeit to the detriment of in-person relations. The teaching staff attempted to uphold the criteria developed in preceding school years, construing the difficulties as challenges. The satisfaction derived from both students' minor achievements and team coordination to devise imaginative alternatives served as an incentive to rise to new challenges.
\end{abstract}

\title{
Key words
}

Covid-19. Combined schooling. In-person care. ICT-mediated care.

\section{Introducción}

Fuimos confinados. Aunque a posteriori pudiéramos haber reconocido indicios sospechosos, el advenimiento de la pandemia a causa de la covid-19 nos tomó por sorpresa a la mayoría. Por sorpresa y fulminantemente. En marzo del año 2020, en menos de una semana, los rumores primero, las noticias luego y las confirmaciones finalmente nos mandaron literalmente a casa de un día para el otro, dejando atrás todo aquello que no consideramos importante y urgente. Ciertamente, se tenía mucha información personal y laboral almacenada en repositorios virtuales, pero las actividades fácticas (esencialmente manipulativas, de contacto y personalizadas) debieron anularse de súbito. Con dudas al principio, pero pronto, ineludiblemente, tuvimos que posponer y anular los compromisos contraídos con personas y entidades para realizar proyectos participativos que habíamos previsto con antelación. Globalmente, se era consciente de que algo se había roto, y una marea nos estaba inundando sin conocer su recorrido ni su empuje. Fue particularmente impactante la supresión de aquellas iniciativas en las que estaban implicadas muchas personas (congresos internacionales, eventos nacionales, espectáculos locales) por la prohibición de mantener encuentros multitudinarios que imposibilitaban la distancia de seguridad señalada por las autoridades sanitarias y, quizás menos mediáticas 
pero más inquietantes, las negativas a realizar reuniones laborales y encuentros familiares y sociales.

Los diversos gobiernos, cogidos también a contrapié en la gestión del conflicto, tuvieron que enfrentarse a un trilema irresoluble. Decidir entre salvaguardar la salud de la población, la economía o las libertades individuales. En función del vector que se alzase como prioritario, las medidas aplicadas eran el exponente del carácter cultural, histórico y político de la sociedad, más liberal o más autoritario. En la toma de decisiones, siempre compleja, la desestimación de cualquier factor perturbó innegablemente los logros sociales conseguidos honrosamente con nuestro esfuerzo y con el de generaciones anteriores a la nuestra. La crisis no era solo de salud o económica, sino de modelo sanitario y de modelo de la economía, y, sobre todo, era una crisis de valores humanos.

\section{Proyecto educativo para el curso 2020-2021}

El inicio del curso 2020-2021 no llegó con mejores perspectivas sanitarias, ya que las olas de la pandemia seguían sucediéndose al son de las más o menos amplias posibilidades de contacto y de movilidad personales. De todos modos, con la experiencia (casi un experimento) de encierro domiciliario incorporada, hecho un balance de beneficios y perjuicios, valorando la salud no solo física sino también mental y social de las familias, se había alcanzado un acuerdo casi unánime de mantener abiertos los centros escolares como espacios de juego, de aprendizaje y de convivencia absolutamente necesarios para los niños y los jóvenes. Eso sí, se propusieron aplicaciones móviles para el rastreo y control de los contactos positivos (entiéndase positivo como negativo). Se habilitaron entradas y salidas diferenciadas y escalonadas para todo el personal. Se clausuraron las fuentes públicas hasta entonces compartidas. Se obligó el uso de mascarillas buconasales para alejar el foco de la transmisión. Se instauró el reglamento de tomar la temperatura y lavar las manos con hidroalcohol frecuentemente. Se establecieron grupos burbuja para poder hacer el seguimiento del contagio en caso de suceder y para preservar a los demás grupos de la expansión del virus. Se limitaron los contactos prescindibles y aun los vinculares entre amigos y familiares. Los profesionales educativos que intervenían en las aulas se restringieron, unificando en un solo tutor las diferentes especialidades, y se permitieron los apoyos externos - como el de los profesionales del Servicio Educativo CREDV-CRE ONCE Barcelonasiempre observando el protocolo de máxima prevención y de trazabilidad constante.

Ruf, A. (2021). El servicio de escolaridad combinada de la ONCE en Cataluña en época de pandemia: adaptar las formas respetando los criterios. RED Visual: Revista Especializada en Discapacidad Visual, 77, 228-239. https://doi.org/10.53094/HPTG3964. 
Los responsables sanitarios y educativos aseguraron que los centros educativos eran lugares seguros para la salud.

Aunque pasados los primeros meses de cierre los centros educativos se consideraron servicios esenciales y se trabajó para mantenerlos como espacios libres de covid-19, en distintas comunidades autónomas y en países cercanos al nuestro se decidieron clausuras temporales justificadas por las inestables curvas crecientes de incidencia de contagios. Como en toda sociedad plural, hubo reacciones opuestas. Diferentes colectivos se organizaron y reclamaron tanto el derecho de continuidad de las actividades presenciales los unos, así como la prolongación del confinamiento domiciliario para sus hijos los otros.

Algunas opciones educativas complementarias, como el SEC del CREDV-CRE ONCE Barcelona fueron reducidas, pospuestas o anuladas presencialmente, viéndose obligadas a proponer otras estrategias metodológicas.

\section{Propuesta para el SEC}

Los alumnos que precisan acudir al SEC son aquellos cuyas circunstancias personales y familiares o educativas y sociales no favorecen la mejor inclusión posible en su entorno. Al margen del apoyo regular personalizado que reciben del Servicio Educativo CREDV-CRE ONCE Barcelona, se hacen acreedores de un apoyo suplementario a través de un soporte global por inmersión. El maestro de apoyo y la familia, junto con el consentimiento de la alumna o del alumno, solicitan la participación del SEC para obtener, sobre todo, recursos personales. EI SEC está formado por un equipo específico de maestros y técnicos que atienden uno o dos días por semana al alumno en el Centro de Recursos Educativos. Allí coinciden con otros alumnos y alumnas de características similares y comparten, durante uno o dos cursos, la asistencia a este Servicio. EI SEC no es solo un lugar. EI SEC es una experiencia que imprime carácter. EI SEC es, paradójicamente, una mirada desde la ceguera a todas las actividades que los alumnos realizan en su seno. Los profesionales del SEC forman un equipo multidisciplinar, aportando cada uno su disciplina y conocimiento en beneficio del desarrollo de los muchachos. Ellos se sienten acogidos, a la vez, de forma singular y plural. Así, se escucha a las madres, a los padres, a los abuelos, a los hermanos mayores, incluso a las acompañantes profesionales que comparten informaciones, experiencias o proposiciones sobre acontecimientos de los niños y las niñas. Se habla

Ruf, A. (2021). El servicio de escolaridad combinada de la ONCE en Cataluña en época de pandemia: adaptar las formas respetando los criterios. RED Visual: Revista Especializada en Discapacidad Visual, 77, 228-239. https://doi.org/10.53094/HPTG3964. 
a los pequeños y jóvenes con discapacidad visual desde el conocimiento de que la voz tiene un poder fundamental en la relación con los demás. Se les insiste en el orden y en las rutinas como facilitadores del control del entorno. Se persevera en la promoción de la autonomía y en el desarrollo de las capacidades para alcanzarla como requisito imprescindible para conseguir la libertad de movimientos y de decisiones. Se promueve la convivencia y la resolución de conflictos como estrategia para convivir con la comunidad con una personalidad e identidad propias. Se favorece el sentimiento de pertenencia a un colectivo de personas con capacidades especiales.

Conservábamos el equipo de profesionales, al margen de algún cambio por motivos personales, e, inicialmente, sin ningún profesional directamente afectado por coronavirus. En cuanto al alumnado, se optó por mantener el mismo conjunto que había finalizado abruptamente su escolaridad combinada en el curso anterior, aun con algunas bajas. Al menos hasta que tuviéramos organizado y probado un nuevo sistema que debíamos ingeniar. Éramos conscientes de las peticiones que nos aguardaban a causa de las imperiosas necesidades que sobrevenían con nuevas detecciones de alumnos con acelerados procesos de pérdida de visión, pero se tuvo que escoger la prudencia frente al atrevimiento ante la posibilidad muy real de cambios bruscos en los protocolos sanitarios.

De pronto todo era internet. Se consumían series televisivas, se asistía a la ópera desde el comedor, se hacía gimnasia mirando el ordenador, se jugaba en línea, se hablaba con los familiares lejanos a través del teléfono móvil. La tenencia de datos o la potencia de wifi marcaban la diferencia entre unas familias que contemporizaban su estancia en casa y otras que quedaban aisladas y apuntaban problemas de salud mental.

Tal como habíamos tenido que admitir precipitadamente los adultos o como ya estaban practicando adolescentes y jóvenes, ensayamos con los niños contactos telemáticos. No tuvimos tantas dudas para la etapa de educación secundaria, pero sabíamos las limitaciones para implementar el aprendizaje en educación primaria a través de un ordenador; en mayor medida en tanto en cuanto siempre habíamos defendido la relación personal que favorece el roce, la amistad y el conflicto, elementos esenciales de un continuo que nos permite madurar como seres humanos.

El mayor reto fue imaginarse cómo trabajar el aprendizaje del braille (una actividad eminentemente táctil) a distancia. Pero no fueron menores las dificultades técnicas de 
conectividad a través de internet y la falta de formación informática que reconocíamos, sobre todo, en los alumnos entre los 6 y los 12 años. La tiflotecnología se alzó como premisa imprescindible y como valor añadido de formación y aprendizaje.

Se inició el SEC con la confianza y la colaboración de las maestras de apoyo itinerantes. Ellas prepararon el terreno para que desde el SEC pudiéramos conectar con los alumnos en horario lectivo mientras estaban en sus escuelas con su grupo de referencia. En algunos casos se dispuso de un espacio más reservado, pero en otros se tuvo que empezar dentro del aula donde se impartía clase simultáneamente a todo el grupo. Las maestras de apoyo itinerantes gestionaron su agenda para poder estar con el alumno o la alumna facilitándole la conexión a través de la red de comunicación. Se desestimaron las conexiones extraescolares en el domicilio porque se consideró que había saturación del uso de las pantallas para los niños y de responsabilidades académicas para los padres, y la oferta hubiera sido poco pedagógica. En un caso de $2 .^{\circ}$ curso de educación primaria fue la misma tutora del colegio la que asumió el apoyo a la conexión entre el alumno y el SEC, y luego él trabajó con suficiente autonomía, usando auriculares para no interferir con la tarea del grupo. Ese era nuestro objetivo también: promover la independencia del alumno con discapacidad visual para que pudiera establecer contacto con otros recursos no presenciales con la mínima ayuda necesaria. Los profesionales del SEC establecieron conexión con los alumnos previo acuerdo con las escuelas. Durante el primer trimestre de curso se hicieron llamadas individuales con la participación de una o de dos maestras al unísono o en tiempo secuenciado. Excepcionalmente, y con el compromiso de evitar la interacción entre ellas para eludir el contagio, tres alumnas se desplazaron físicamente al CRE para mantener sesiones de apoyo psicológico y se aprovechó su traslado para trabajar individualmente requisitos imprescindibles en el manejo del ordenador.

Es justo mencionar que descubrimos posibilidades desconocidas de la tecnología. En primer lugar, se pudo acceder a alumnos que habíamos desestimado en atención presencial porque vivían en distintas provincias y estaba prohibido cruzarlas sin una justificada causa mayor. La plataforma de videollamadas Zoom permitió asimismo la comunicación entre profesionales ciegos y alumnos con discapacidad visual, accediendo ambos a la voz de cada uno de ellos y el profesional a la voz del programa JAWS del alumno, con lo que podía controlar las eventualidades que sucedían a kilómetros de distancia. Con la aplicación JAWS Tandem pudieron compartir espacio de trabajo y

1 No se utilizan los términos clases o formación porque dichos conceptos reducen la dimensión integral del Servicio.

Ruf, A. (2021). El servicio de escolaridad combinada de la ONCE en Cataluña en época de pandemia: adaptar las formas respetando los criterios. RED Visual: Revista Especializada en Discapacidad Visual, 77, 228-239. https://doi.org/10.53094/HPTG3964. 
supervisar el manejo del dispositivo además de las tareas encomendadas. O simplemente con cualquier programa que compartiera la pantalla se podían mostrar ejemplos o recomendaciones. Para el aprendizaje del braille o para trabajos manipulativos, anticipábamos a través de la maestra de apoyo itinerante los materiales necesarios, y el día de la conexión las actividades eran supervisadas por profesionales especialistas del SEC. Esta presencia virtual, que nosotros consentíamos a regañadientes, fue luego valorada por los profesionales como motivadora para el niño. Y tuvimos que admitir que habíamos sacado provecho de unas condiciones inicialmente adversas.

\section{Adaptación metodológica para los alumnos en el SEC}

Hasta marzo del año 2020, el SEC se materializó en el CRE: alumnos y acompañantes salían pronto de sus casas y se desplazaban en coche, en moto o en transporte público, dejando atrás su colegio o instituto habitual; confluían en la recepción (donde se encontraban aún medio dormidos niños y niñas, madres y padres); aquellos se dirigían al ascensor subiendo con las educadoras; entraban en la sala de acogida donde cogían sus bártulos; iban a las aulas donde se iniciaba la liturgia del aprendizaje; continuaban en el taller de plástica; coincidían en la zona de intercambio (una especie de hub), donde fluían las conversaciones espontáneas; bajaban al patio inferior, donde se desayunaba; subían al mediodía al patio superior soleado en el que se reunían los grupos con naturalidad; se concentraban en el comedor donde se alimentaba también la convivencia y se recitaban poesías; acudían al despacho de la psicóloga, del que salían reconfortados; bajaban de nuevo al aula de informática, donde la motivación era una aliada; caminaban hasta el polideportivo, donde se jugaba, se reía, se esforzaban, se aprendía, se vivía...

Los alumnos que habían sido propuestos para el SEC relataban a final de curso que «habían estado» en el SEC, una manera de decir que pertenecían a un colectivo especial. Habían sido elegidos para compartir con niñas y niños de otros centros una experiencia diferente en un sitio diferente con profesionales diferentes, aunque iguales en la voluntad de construir una identidad propia. Cuando regresaban a sus escuelas, los compañeros de clase les podían preguntar el motivo de su falta al centro el día anterior o donde habían estado, y ellos se sentían protagonistas de una vivencia singular que a veces compartían y a veces guardan celosamente. Habían estado en el SEC.

Uno de los objetivos del SEC era, precisamente, ofrecer a los alumnos confianza, recursos y estrategias para manejarse en su entorno habitual con criterio, desen-

Ruf, A. (2021). El servicio de escolaridad combinada de la ONCE en Cataluña en época de pandemia: adaptar las formas respetando los criterios. RED Visual: Revista Especializada en Discapacidad Visual, 77, 228-239. https://doi.org/10.53094/HPTG3964. 
voltura y positividad. Alguno de ellos llegaba al SEC con el desánimo, la confusión y la inseguridad fruto de la aparición de la ceguera. Otros arrastraban intervenciones médicas, problemas escolares, conflictos familiares y desarraigo cultural. Todos, en general, adolecían de un buen progreso académico, pero no era más que el exponente de un desarrollo personal complicado y poco inclusivo.

El punto de inflexión que marcó la covid-19 obligó a ofrecer ese apoyo más global del SEC a los alumnos, a sus familias y a las maestras itinerantes de otra manera diferente. La característica que, de modo lacerante, describía el SEC actual en época de confinamiento era el trabajo individualizado, sin relación con otros compañeros con discapacidad visual que atravesaban igualmente momentos delicados en sus vidas. Más porque la sociedad en la que vivimos escora hacia el individualismo hedonista e insolidario, y la edificación y el mantenimiento de diques contra la exclusión y la barbarie reclaman todos los recursos posibles. Ese rasgo identitario del SEC que durante los cursos anteriores habíamos construido y defendido como preciado valor, ahora debía descartarse por una situación inédita que ni en las peores pesadillas hubiéramos sido capaces de imaginar. Acatando las circunstancias y conscientes de que había que avanzar sin tener demasiado tiempo para elaborar duelos, tuvimos que proponer soluciones personalizadas renunciando al funcionamiento de grupo, al cual otorgábamos un alto valor educativo. Las chicas y chicos acogieron gratamente nuestra propuesta de conexión virtual. Venían de confinamientos totales en sus casas y de un verano con restricciones de movilidad. A pesar de su ingenuidad dúctil y de su capacidad de adaptación, se hacían partícipes también de lo que sucedía con los adultos que se tapaban la boca con mascarillas, evitaban el contacto directo con otras personas, estaban asimismo enclaustrados, perdían sus trabajos, no podían ser atendidos en servicios médicos, tristemente veían morir a familiares sin compañía, perdían la esperanza cada día que pasaba...

\section{Respeto a los criterios profesionales}

Aunque en la primera reunión virtual los profesionales del equipo hubiéramos estado todos presentes -eso sí, acomodados en nuestras casas o encerrados en nuestros despachos unipersonales-, la experiencia del encuentro en la sala de reuniones, en disposición circular, sentados en sillas escolares y negociando la temperatura del aire acondicionado no se repitió. Faltaron los sutiles matices, las sugerencias, los comentarios al margen, las intuiciones, las miradas de asentimiento o de extrañeza, la prosodia,

Ruf, A. (2021). El servicio de escolaridad combinada de la ONCE en Cataluña en época de pandemia: adaptar las formas respetando los criterios. RED Visual: Revista Especializada en Discapacidad Visual, 77, 228-239. https://doi.org/10.53094/HPTG3964. 
en fin, de una comunicación que se alimenta no solo de palabras y de bustos sino de cuerpos enteros, de maneras de estar y de complicidades cercanas. Nadie sabía cómo empezar. No teníamos experiencia previa y estábamos personalmente afectados por todo lo que estaba sucediendo. Direcciones y técnicos habían redactado planes de contingencia: supuestos virtuales, semipresenciales y presenciales, concretando los detalles de las personas que podían estar en espacios cerrados que previamente se habían medido. Las posibilidades de reunir alumnos de diferentes procedencias (como se había hecho hasta entonces) eran remotas si no prohibidas. De todos modos, aunque propusimos también distintas opciones para supuestos más o menos favorables, finalmente tuvimos que elegir el más cauto, el menos expuesto, el de celebrar el SEC a distancia y renunciar al presencial con alumnos de poblaciones y escolarizaciones distintas. De todos modos, nunca abandonamos el compromiso de ejecutar el Servicio, aunque se planteó la posibilidad. Retrasamos, eso sí, algunas tareas, pero continuamos explorando maneras de hacer que no pervirtieran el sentido del SEC.

El contacto entre el equipo de profesionales se mantuvo en reuniones telemáticas y con encuentros telefónicos y presenciales individuales. Durante los cursos anteriores, nuestras reuniones habían perseguido la construcción de un modelo técnicamente eficiente, profesionalmente estimulante y éticamente responsable. Se intentó mantener este espíritu a pesar de las dificultades que acusábamos en los diálogos a través de la pantalla. Además de la transmisión de informaciones y la inevitable negociación para pergeñar una propuesta de Servicio coherente implicando a todos los participantes, procuramos continuar con el debate sobre qué era el SEC y qué objetivos perseguía. Mantuvimos, en la medida de nuestras posibilidades, el apoyo al alumno, el apoyo a la familia, el apoyo a la maestra de apoyo y el apoyo al centro educativo.

Uno de los temas que ocupaba nuestras mentes era el planteamiento recurrente sobre si la atención segregada a los alumnos un día a la semana, fuera de su escuela, favorecía la inclusión en su comunidad. Entendíamos en general que sí, pero había alumnos que, por más asistencia que tuvieran al SEC, modificaban poco sus circunstancias en el contexto habitual. Teníamos que aceptar que aun haciendo nuestro trabajo correctamente, habría siempre factores que difícilmente podríamos modificar. Lo que sí que éramos capaces de asegurar era que los alumnos vivían en el SEC una experiencia única que les hacía sentirse acogidos y que fortalecía su autoestima. Teníamos ahora, con la pandemia, una oportunidad de evaluar si el SEC realizado con los alumnos en sus escuelas conseguía los mismos resultados que con su asistencia al CRE un día a la semana.

Ruf, A. (2021). El servicio de escolaridad combinada de la ONCE en Cataluña en época de pandemia: adaptar las formas respetando los criterios. RED Visual: Revista Especializada en Discapacidad Visual, 77, 228-239. https://doi.org/10.53094/HPTG3964. 


\section{Encarar las adversidades que afectaron también al SEC}

La realidad suele imponerse a la ficción. El inicio del curso 2020-2021 no estuvo exento de nuevas demandas de apoyo de alumnos con discapacidad visual al CRE. A algunos de ellos, la circunstancia de la pérdida de visión les había sobrevenido durante la ausencia escolar de marzo a junio, es decir, que en el retorno a las aulas en septiembre se hizo patente una situación que habrían vivido como un oculto viacrucis personal. Si a ello añadimos que los servicios de atención personal entraron en ERTE y luego tuvieron que adoptar todo un paquete de medidas restrictivas para atender a los usuarios, los trámites para las peticiones se enlentecieron y la provisión de recursos se retrasó o se redujo. El sufrimiento de las familias fue más intenso, si cabe, y a las personas más frágiles les costó más sobrellevar la angustia. Se intentó paliar esa circunstancia, pero tanto la falta de medios adecuados como la inexperiencia ante una crisis inusitada exigieron un enorme esfuerzo por parte de todos los profesionales concernidos.

Al SEC le llegaron finalmente estas peticiones de apoyo extraordinario y se recogieron con el exiguo patrimonio de los ensayos realizados durante el primer trimestre de curso con unos pocos alumnos dispersos. Debido a sus características, algunos de los alumnos que solicitaban el Servicio no podían acceder a los supuestos de atención presencial en el CRE (por la imposibilidad de ser acompañados o por la lejanía con el domicilio) ni a la atención telemática a través del ordenador (por falta de conexión, de dispositivos o de habilidad para su manejo). La solución, planteada quizás intempestivamente, fue salir a buscarlos. El equipo abordó con ciertas dudas el debate de la propuesta, pero aceptó el compromiso de asistir a los más desfavorecidos. Como un deber ético y como una obligación profesional que debía organizar los recursos humanos disponibles en función de las necesidades planteadas y valoradas. Eran muchas las presuposiciones de nuestro proyecto pedagógico que debían aplazarse, y temíamos que los hechos consumados menospreciaran nuestras convicciones y nos obligaran a mantener unas actuaciones que aceptábamos -casi siempre con objeciones- porque creíamos que serían temporales y reversibles. Por ello, la inercia de lo consuetudinario nos frenaba de admitir propuestas de intervención alejadas de aquellas que considerábamos probadas y eficientes durante cursos anteriores. De todos modos, no cabía alternativa. La pandemia no remitía y la única opción opuesta a la parálisis era el valor, y estábamos presenciando muchos ejemplos en esa dirección, tanto en el ámbito personal como en el social, en el sanitario y en el cultural, y el educativo no podía ser menos. Los perfiles profesionales distintos se complementaban y,

Ruf, A. (2021). El servicio de escolaridad combinada de la ONCE en Cataluña en época de pandemia: adaptar las formas respetando los criterios. RED Visual: Revista Especializada en Discapacidad Visual, 77, 228-239. https://doi.org/10.53094/HPTG3964. 
en esta coyuntura, unos y otros entendieron cuál era el objetivo de nuestra atención. Las renuncias profesionales, si las hubo, revirtieron en el fortalecimiento de una causa común hacia los alumnos con discapacidad visual.

Lo intentamos. Finalmente, no fue posible, pero, de todos modos, lo intentamos. Otras urgencias reclamaron nuestro esfuerzo y tuvimos que priorizar. El análisis de necesidades era adecuado, pero los recursos disponibles insuficientes. La creciente demanda global de nuevos usuarios afectaba a todos los equipos del CRE, y los profesionales del SEC no eran una excepción. Les necesitaban para otros compromisos previos o imperiosos. Hubo que decidir qué requerimientos se atendían primero, y tuvimos que limitar la oferta de apoyo del SEC. No pudimos desplazar profesionales al territorio para atender casos individuales. Se tuvo, por contra, que acotar el apoyo a aquellos que pudieran asistir al CRE (aun en tiempo limitado) o a aquellos que pudieran conectarse telemáticamente. En ambos casos se precisaba la colaboración de los diversos agentes implicados: alumno, familia, centro educativo y maestro itinerante de apoyo. Definitivamente, el objetivo del SEC, la mejor inclusión para cada uno de los alumnos, no era tampoco posible sin la responsabilidad de todos.

EI SEC ofreció su colaboración a las maestras de apoyo y al alumnado evaluando las peticiones y los recursos disponibles. Unos pocos alumnos pudieron acercarse al CRE y ser atendidos presencialmente con trato individual (los de educación secundaria por sus propios medios, trabajando la autonomía de desplazamiento, y los de educación primaria acompañados por sus madres o padres). Otros se conectaron por videollamada y trabajaron actividades específicas con el orgullo de dominar una técnica comunicativa inédita hasta el momento. Todos fueron partícipes de un ensayo del cual se obtuvo una experiencia gratificante. Esta era el preludio de un aprendizaje necesario y útil para un futuro cercano hacia el cual se dirigía toda la población y para el que los alumnos con discapacidad visual debían llegar preparados si querían obtener un billete inclusivo.

\section{Epílogo}

Era evidente que la pandemia estaba golpeando con fuerza a las capas sociales más desfavorecidas y que los servicios sociales afrontaban una vez más una crisis sin precedentes. La diferencia era que, esta vez, nos afectaba de cerca a nosotros, incluidos en los países del autodenominado estado del bienestar. Siendo, pues, a la

Ruf, A. (2021). El servicio de escolaridad combinada de la ONCE en Cataluña en época de pandemia: adaptar las formas respetando los criterios. RED Visual: Revista Especializada en Discapacidad Visual, 77, 228-239. https://doi.org/10.53094/HPTG3964. 
vez, demandantes y demandados de ayuda, teníamos, por un lado, que reconocer nuestras limitaciones como Servicio y, a la par, debíamos reclamar mayor dedicación en el auxilio a las personas. De alguna manera, la sociedad civil había demostrado su compromiso con las redes de apoyo establecidas espontáneamente. Las administraciones debían dar también un paso adelante en la obligación de dedicación estructural a la infancia, a la vejez, a la discapacidad, a la vulnerabilidad, en fin, a todos nosotros, los humanos.

No podíamos imaginar que aquel inocente juego de entretenimiento infantil en el que, ante un ficticio ultimátum, debíamos escoger entre salvar a una mujer joven embarazada, a un prestigioso científico, a un agricultor, a un médico jubilado, a un dirigente político o a un reconocido artista llegaría a convertirse en un escenario real. En el contexto actual, decidir a quién se administra la vacuna del coronavirus podría asemejarse a clasificar a los seres humanos por un orden de prelación vital. Esta clasificación nos incumbe a todos y es el exponente de nuestros valores, principios y creencias. Se puede hacer la elección con criterios de vínculo familiar, de solidaridad con los más débiles, de eficiencia en los resultados, de balance entre los beneficios y los perjuicios, de protección a determinadas personas o colectivos, con criterios económicos, por franjas de edad, por la consideración de realizar servicios esenciales, por compensación a trabajos de riesgo efectuados, por la posibilidad de sobrevivir ante la eventualidad de una mortandad generalizada, etcétera.

De momento, a la vista de la escasez de suministros vacunales, la población admite o acata los criterios que esgrimen las autoridades con la esperanza de que, en un plazo relativamente breve, la mayoría de ciudadanos habrá sido vacunada. Así lo confirman los políticos, pero su credibilidad es dudosa y las vicisitudes muchas. Si queremos ser no solo una sociedad civilizada sino decente, tal como afirma Margalit (1997), las instituciones no deberían humillar a las personas.

\section{Referencias bibliográficas}

Margalit, A. (1997). La sociedad decente. Paidós.

Albert Ruf Urbea. Pedagogo. CREDV-Centro de Recursos Educativos de la ONCE en Barcelona. Gran Via de les Corts Catalanes, 394; 08015 Barcelona (España).Correo electrónico: aru@once.es.

Ruf, A. (2021). El servicio de escolaridad combinada de la ONCE en Cataluña en época de pandemia: adaptar las formas respetando los criterios. RED Visual: Revista Especializada en Discapacidad Visual, 77, 228-239. https://doi.org/10.53094/HPTG3964. 